\title{
(2) OPEN ACCESS \\ Antidopaminergic treatment is associated with reduced chorea and irritability but impaired cognition in Huntington's disease (Enroll-HD)
}

\author{
Kate L Harris @ (1) 'Wei-Li Kuan, ${ }^{1}$ Sarah L Mason, ${ }^{2}$ Roger A Barker ${ }^{3}$
}

\begin{abstract}
- Additional material is published online only. To view please visit the journal online (http://dx.doi.org/10.1136/ jnnp-2019-322038)

'Department of Clinical Neurosciences, The University of Cambridge, Cambridge, United Kingdom

${ }^{2}$ Department of Clinical Neurosciences, Cambridge Centre for Brain Repair, Cambridge, United Kingdom ${ }^{3}$ Department of Clinical Neurosciences, John van Geest Centre for Brain Repair, and MRC-WT Cambridge Stem Cell Institute, University of Cambridge, Cambridge, United Kingdom
\end{abstract}

Correspondence to Kate L Harris, Clinical Neurosciences, The University of Cambridge, Cambridge CB2 1TN, UK; kh600@cam.ac.uk

SLM and RAB are joint senior authors.

Received 10 September 2019 Revised 26 February 2020 Accepted 13 March 2020 Published Online First 30 March 2020

Check for updates

(c) Author(s) (or their employer(s)) 2020. Re-use permitted under CC BY-NC. No commercial re-use. See rights and permissions. Published by BMJ.

To cite: Harris KL, Kuan W-L, Mason SL, et al. J Neurol Neurosurg Psychiatry 2020:91:622-630

\section{ABSTRACT}

Objectives Alterations in dopamine neurotransmission underlie some of the clinical features of Huntington's disease (HD) and as such are a target for therapeutic intervention, especially for the treatment of chorea and some behavioural problems. However, justification for such an intervention is mainly based on case reports and small open label studies and the effects these drugs have on cognition in HD remain unclear.

Methods In this study, we used the Enroll-HD observational database to assess the effects of antidopaminergic medication on motor, psychiatric and cognitive decline, over a 3-year period. We first looked at the annual rate of decline of a group of HD patients taking antidopaminergic medication $(n=466)$ compared with an untreated matched group $(n=466)$. The groups were matched on specified clinical variables using propensity score matching. Next, we studied a separate group of HD patients who were prescribed such medications part way through the study $(n=90)$ and compared their rate of change before and after the drugs were introduced and compared this to a matched control group.

Results We found that HD patients taking antidopaminergic medication had a slower progression in chorea and irritability compared with those not taking such medications. However, this same group of patients also displayed significantly greater rate of decline in a range of cognitive tasks.

Conclusion In conclusion we found that antidopaminergic treatment is associated with improvements in the choreic movements and irritability of HD but worsens cognition. However, further research is required to prospectively investigate this and whether these are causally linked, ideally in a double-blind placebo-controlled trial.

\section{INTRODUCTION}

Huntington's disease (HD) is an autosomal dominant neurodegenerative disorder caused by an expanded CAG (cytosine-adenine-guanine) repeat in the HTT gene (mHTT) on chromosome 4. Involuntary movements are a classical feature of HD although cognitive and psychiatric impairments along with other neurological changes are also a prominent early feature of the disease and place significant burden on patients and their families. Cognitive deficits include a loss of higher-order 'executive functions' such as attention, planning, flexibility and memory, ${ }^{12}$ as well as compromised emotional processing ${ }^{3}$ and visuospatial perception. ${ }^{1}$ In more advanced stages an overall cognitive decline is observed leading to dementia in the majority of patients. Psychiatric impairments including irritability, obsessive and perseverative behaviours, apathy and depression ${ }^{4-6}$ are evident at all stages of the disease. ${ }^{78}$

HD is defined pathologically by the dysfunction and subsequent loss of neurons, most notably, in early stage disease, in the striatum and cortex ${ }^{910}$ areas which receive a significant dopaminergic input. ${ }^{11}$ Paradoxically, while there is an early loss of postsynaptic dopamine (DA) receptors at these sites, one of the most effective and widely used therapies involves DA blocking/depleting agents especially for chorea. ${ }^{6}$ However, the empirical evidence for this approach is lacking. Only tetrabenazine has been subjected to formal efficacy trials, and its use is associated with an increased risk of depression and anxiety. ${ }^{12}$

It is well known that in addition to its role in motor function, DA is also critical for higher-order cognitive processes, in particular executive function $^{13}$ as well as psychiatric symptomatology such as psychosis, motivating effortful behaviour, reinforcement learning and reward processing. ${ }^{14} 15$ Regarding cognitive function, it has been postulated that DA modulates this in an inverted $U$ function fashion, whereby both excessive and insufficient cortical levels perturb performance. ${ }^{16}$ Therefore, aberrant DA signalling may also contribute to the cognitive disturbances in HD, although this has not been well studied. ${ }^{17}$ It is thus possible that antidopaminergic treatment targeted at the motor impairments of HD also has an impact on non-motor features of the disease.

We therefore sought to investigate the effect of antidopaminergic medication on motor, cognitive and psychiatric decline in HD using the Enroll-HD database. We found that the introduction of these medications was associated with improvements in chorea and irritability but a decline in cognition.

\section{METHODS}

In this study, data were analysed from the CHDI Foundation Enroll-HD study (https://www.enrollhd.org). Enroll-HD is a longitudinal, observational, multinational study of HD gene carriers who undergo an annual appointment which includes a review of current medication and a battery of motor, cognitive and psychiatric assessments. Our 
analysis was performed on the fourth data cut comprising 15 302 participants with an average of 2.4 visits (ranging from 1 to 6 visits). In the study, motor features are scored using the Unified Huntington Disease Rating Scale (UHDRS '99; Huntington Study Group, 1996). Psychiatric features are assessed using the problems behavioural assessment (PBA) and the depression, irritability and apathy sub-scores from this were used in this study. Cognitive assessments include the symbol digit modalities test (SDMT), phonemic verbal fluency, Stroop and trail making tasks. ${ }^{18}$ In this paper, we assign a composite 'total cognitive score' for each individual by transforming the raw scores for each cognitive task into z-scores $(z=(x-\mu)$ $(\sigma)$ and adding them together to create a single $z$-score per patient. When calculating z-scores, the two groups (antidopaminergic medication takers and non-antidopaminergic medication takers, outlined in detail below) were pooled together in order to calculate the population mean and SD. Results for individual cognitive task scores are found in the online supplementary section.

\section{Data analysis}

The data were filtered to include only manifest HD patients, over the age of 18 , with a CAG repeat length of $36-55(n=8004)$. Participants with at least two complete visits $(n=5011)$ were sorted into two groups, those taking antidopaminergic medication during the period of data collection $(\mathrm{n}=2369)$, and those not taking antidopaminergic medication for the entire period $(n=2642)$. Next, propensity score matching was performed, whereby the two groups were matched for age, CAG repeat length, total functional capacity (TFC) score and time since diagnosis using the 'match it' plugin for $\mathrm{R}$ statistical software. The 'nearest neighbour' matching command was used, which selected the most closely matched control for each participant in the antidopaminergic medication group ( $n=466$ per group).

We also investigated whether those starting antidopaminergic medication part way through the study exhibited changes in the rate of motor, cognitive and psychiatric decline following medication introduction. Individuals with at least two visits prior to taking antidopaminergic medication and two visits while taking the medication $(n=90)$ were included. Again, we used propensity score matching to match these individuals with a clinically comparable control group to give an indication of the average change in score for each assessment over the same 4-year period. Table 1 outlines the antidopaminergic medications included in the analysis.

\begin{tabular}{|c|c|c|}
\hline \multirow[b]{2}{*}{ Drug } & \multicolumn{2}{|c|}{ Number of patients on each drug } \\
\hline & Group $1(n=466 *)$ & Group $2\left(n=90^{*}\right)$ \\
\hline On two or more of the below & 175 & 53 \\
\hline Tetrabenazine & 188 & 28 \\
\hline Sulpiride & 34 & 16 \\
\hline Haloperidol & 66 & 19 \\
\hline Olanzapine & 156 & 49 \\
\hline Tiapride & 118 & 27 \\
\hline Risperidone & 98 & 51 \\
\hline Quetiapine & 45 & 8 \\
\hline
\end{tabular}

Group 1: patients on antidopaminergic medication throughout the study. Group 2: patients started on antidopaminergic medications part way through the study.

*Some patients were on more than one of the drugs.

\section{Statistical analysis}

Baseline demographics between treatment and control groups were compared using t-tests. For multivariate analyses, parametric methods were used due to there being a sufficiently large sample size. The annual change in score for each assessment was calculated for every patient and their average score for each assessment across visits was taken. The point change in cognitive, motor or psychiatric performance for each participant was calculated by subtracting the first assessment score from the last assessment score. A patient's average score for each assessment across visits was then taken.

\section{Group 1: HD antidopaminergic takers $(n=466)$ and HD controls} (non-antidopaminergic takers) $(n=466)$

For each assessment, the average rate of change of the two groups was compared using a univariate ANOVA with change in score as the dependent variable, group (antidopaminergic medication takers vs non-antidopaminergic medication takers) as the independent variable and age, CAG repeat length and gender as covariates. The resulting p-values were then corrected for multiple comparisons (and the associated risk of type 1 errors), using the false discovery rate method, with a threshold set at $5 \%$ $(\mathrm{q}<0.05)$. To assess which factors predict the annual change in composite cognitive score, a multivariate linear regression was used with the addition of the following variables: group, CAG repeat length, gender, age, disease burden score (DBS), TFC score, time since diagnosis, UHDRS motor score, depression, apathy and irritability scores. Psychiatric measures were included as they can affect cognitive abilities, likely due to a variety of factors including anhedonia, decreased motivation, concentration difficulties and impairments in attention and processing speed. ${ }^{19}$

In addition to using propensity score matching, we verified our results using covariate adjustment, based on the findings by Elze $e t a l,{ }^{20}$ which showed that this more conventional technique may be the most reliable method for the analysis of observational databases. To do this, we compared the yearly rate of change between the group taking antidopaminergic medication $(n=2369)$ and the group of non-takers $(n=2642)$ using a univariate analysis of variance (ANOVA) with the following covariate variables: age, gender, CAG repeat length, DBS, TFC and time since diagnosis (see online supplementary section). $\mathrm{DBS}=(\mathrm{CAG}$ $-35.5) *$ age. $^{21}$

Group 2: HD pre-antidopaminergic and post-antidopaminergic takers ( $n=90)$ and HD controls (non-antidopaminergic takers) ( $n=$ 104)

These patients had completed four annual assessments, the antidopaminergic subgroup being on medication for the last two assessments only. The rate of change between the first and second year (referred to as time interval 1) was compared with the rate of change between the third and fourth years (time interval 2), using paired t-tests, for both groups separately. Then, for each time interval, the rate of decline of the two groups was compared with a univariate ANOVA with change in score as the dependent variable, group as the independent variable and age, CAG repeat length and gender as covariates. Graphpad Prism software and IBM SPSS statistics V.25 were used to conduct the statistical analysis

\section{RESULTS}

Of the 5011 manifest HD patients included in our analysis, $2369(42 \%)$ were taking antidopaminergic medication. These 
Table 2 Group 1. demographics of participant groups at the first appointment, showing the mean with SD in brackets and range below

\begin{tabular}{|c|c|c|}
\hline & $\begin{array}{l}\text { HD controls (non- } \\
\text { antidopaminergic takers) } \\
(n=466)\end{array}$ & $\begin{array}{l}\text { HD antidopaminergic } \\
\text { takers } \\
(n=466)\end{array}$ \\
\hline Number of visits & $\begin{array}{l}3(1) \\
2-6\end{array}$ & $\begin{array}{l}3.1(1) \\
2-6\end{array}$ \\
\hline Gender ( $m: f$ ) & $234: 232$ & $267: 200$ \\
\hline $\begin{array}{l}\text { ISCED } \\
\text { (educational level) }\end{array}$ & $\begin{array}{l}3.6(1.2) \\
1-6\end{array}$ & $\begin{array}{l}3.5(1.2) \\
1-6\end{array}$ \\
\hline $\begin{array}{l}\text { Age } \\
\text { (years) }\end{array}$ & $\begin{array}{l}54.6(9.7) \\
26-79\end{array}$ & $\begin{array}{l}54.4(9.2) \\
26-79\end{array}$ \\
\hline CAG repeat length & $\begin{array}{l}43(2.1) \\
40-55\end{array}$ & $\begin{array}{l}43.1(2.1) \\
40-55\end{array}$ \\
\hline DBS & $\begin{array}{l}394.4(55) \\
180-573.5\end{array}$ & $\begin{array}{l}397(55.2) \\
180-573.5\end{array}$ \\
\hline TFC score & $\begin{array}{l}9.9(2.4) \\
3-13\end{array}$ & $\begin{array}{l}9.3(2.5) \\
3-13\end{array}$ \\
\hline $\begin{array}{l}\text { Time since diagnosis } \\
\text { (years) }\end{array}$ & $\begin{array}{l}3.4(3.7) \\
0-22\end{array}$ & $\begin{array}{l}3.8(3.7) \\
0-22\end{array}$ \\
\hline $\begin{array}{l}\text { Total motor score UHDRS } \\
\text { Max score } 124\end{array}$ & $\begin{array}{l}28.1(14.6) \\
0-81\end{array}$ & $\begin{array}{l}33.8^{*}(15.5) \\
0-85\end{array}$ \\
\hline $\begin{array}{l}\text { Total chorea score UHDRS } \\
\text { Max score } 28\end{array}$ & $\begin{array}{l}8.2(4.5) \\
0-26\end{array}$ & $\begin{array}{l}9.3^{*}(5.2) \\
0-28\end{array}$ \\
\hline $\begin{array}{l}\text { Irritability } \\
\text { (PBA) } \\
\text { Max score } 32\end{array}$ & $\begin{array}{l}2.5(3.9) \\
0-25\end{array}$ & $\begin{array}{l}3.5^{*}(5.1) \\
0-28\end{array}$ \\
\hline $\begin{array}{l}\text { Depression } \\
\text { (PBA) } \\
\text { Max score } 48\end{array}$ & $\begin{array}{l}4.3(5.8) \\
0-36\end{array}$ & $\begin{array}{l}5.7^{*}(6.7) \\
0-36\end{array}$ \\
\hline $\begin{array}{l}\text { Apathy } \\
\text { (PBA) } \\
\text { Max score } 16\end{array}$ & $\begin{array}{l}2.2(3.4) \\
0-16\end{array}$ & $\begin{array}{l}3.7^{*}(4.4) \\
0-16\end{array}$ \\
\hline $\begin{array}{l}\text { MMSE } \\
\text { Max score } 30\end{array}$ & $\begin{array}{l}26.7(2.7) \\
14-30\end{array}$ & $\begin{array}{l}25.7^{*}(3.3) \\
11-30\end{array}$ \\
\hline Composite cognitive z-score & $\begin{array}{l}1.3(5.3) \\
-21.7 \text { to } 18.9\end{array}$ & $\begin{array}{l}>\quad 1.3(5.8) \\
-\quad 32.4-16.7\end{array}$ \\
\hline
\end{tabular}

ISCED, The International Standard Classification of Education; CAG, cytosine-adenine-guanine; MMSE, Mini-Mental State Examination.

*Indicates a significant difference $(p<0.001)$ when compared with the control non-antidopaminergic medication group

DBS, disease burden score; HD, Huntington's disease; PBA, problems behavioural assessment; TFC, total functional capacity; UHDRS, Unified Huntington Disease Rating Scale.

individuals were on average older, had been diagnosed with HD for longer and were at a more advanced disease stage than those not taking antidopaminergic medication (online supplementary table S1). After propensity score matching, there were no differences between the groups in terms of age, CAG repeat length, TFC score, time since diagnosis, educational level and DBS ( $p>0.05$, see table 2). However, the group on antidopaminergic medication had significantly greater scores for both UHDRS total motor and total chorea scores, and for PBA depression, apathy and irritability scores $(\mathrm{p}<0.001$ for all). Importantly, aside from the total motor score, the differences between groups were small (around a 1-point difference). However, increased motor and psychiatric impairments in this group are expected, since these patients were specifically prescribed this medication to treat these symptoms (with $67 \%$ being prescribed for motor impairments and $28 \%$ for psychiatric impairments, see online supplementary table S3). The antidopaminergic group also had a significantly lower composite total cognitive z-score than the non-antidopaminergic group $(\mathrm{p}=<0.001$, see table 2$)$, and a lower raw score in all of cognitive tasks except Trail making A (see online supplementary table S4), indicating worse performance. It is, therefore, important to note that the group on antidopaminergic medication appear to be at a similar disease stage but with having a more severe disease profile at baseline.

Next, we selected a separate group of patients to investigate whether the introduction of antidopaminergic medication led to
Table 3 Group 2. baseline demographics of participants having two assessments prior to and two assessments subsequent to starting antidopaminergic medication and matched controls, showing the mean with SD in brackets

\begin{tabular}{|c|c|c|}
\hline & $\begin{array}{l}\text { Control group (those not } \\
\text { taking dopamine medication } \\
\text { but assessed at the same } \\
\text { time points) } \\
(n=104)\end{array}$ & $\begin{array}{l}\text { Pre- } \\
\text { antidopaminergic } \\
\text { and post- } \\
\text { antidopaminergic } \\
\text { treatment group } \\
(\mathrm{n}=90)\end{array}$ \\
\hline Number of visits & $\begin{array}{l}4.4(0.6) \\
4-6\end{array}$ & $\begin{array}{l}4.3(0.5) \\
4-6\end{array}$ \\
\hline Gender (m:f) & $52: 48$ & $41: 49$ \\
\hline ISCED & $\begin{array}{l}3.8(1.2) \\
1-6\end{array}$ & $\begin{array}{l}3.5(1.2) \\
2-6\end{array}$ \\
\hline Age & $\begin{array}{l}52.6(12) \\
28-83\end{array}$ & $\begin{array}{l}53(11.3) \\
26-79\end{array}$ \\
\hline CAG repeat length & $\begin{array}{l}42.9(4.9) \\
38-52\end{array}$ & $\begin{array}{l}43.4(2.6) \\
39-51\end{array}$ \\
\hline DBS & $\begin{array}{l}388(78.2) \\
167.5-589\end{array}$ & $\begin{array}{l}392.9(66.1) \\
202.5-567\end{array}$ \\
\hline $\begin{array}{l}\text { TFC score } \\
\text { Max score } 13\end{array}$ & $\begin{array}{l}10.1(3.2) \\
0-13\end{array}$ & $\begin{array}{l}9.2(3.2) \\
0-13\end{array}$ \\
\hline $\begin{array}{l}\text { Time since diagnosis } \\
\text { (years) }\end{array}$ & $\begin{array}{l}4.1(4.2) \\
0-20\end{array}$ & $\begin{array}{l}4(4) \\
0-20\end{array}$ \\
\hline $\begin{array}{l}\text { Motor score (UHDRS) } \\
\text { Max score } 124\end{array}$ & $\begin{array}{l}28.1(18.18) \\
5-95\end{array}$ & $\begin{array}{l}31.3(15.4) \\
7-80\end{array}$ \\
\hline $\begin{array}{l}\text { Total chorea score (UHDRS) } \\
\text { Max score } 28\end{array}$ & $\begin{array}{l}7.8(4.9) \\
0-21\end{array}$ & $\begin{array}{l}9.5^{*}(5) \\
0-21\end{array}$ \\
\hline $\begin{array}{l}\text { Irritability } \\
\text { (PBA) } \\
\text { Max score } 32\end{array}$ & $\begin{array}{l}1.8(2.8) \\
0-13\end{array}$ & $\begin{array}{l}4.3+(5.6) \\
0-24\end{array}$ \\
\hline $\begin{array}{l}\text { Depression } \\
\text { (PBA) } \\
\text { Max score } 48\end{array}$ & $\begin{array}{l}2.7(3.9) \\
0-18\end{array}$ & $\begin{array}{l}4.2^{*}(5.5) \\
0-23\end{array}$ \\
\hline $\begin{array}{l}\text { Apathy } \\
\text { (PBA) } \\
\text { Max score } 16\end{array}$ & $\begin{array}{l}2(3.7) \\
0-16\end{array}$ & $\begin{array}{l}2.8(4.1) \\
0-16\end{array}$ \\
\hline $\begin{array}{l}\text { MMSE } \\
\text { Max score } 30\end{array}$ & $\begin{array}{l}27.5(2.6) \\
17-30\end{array}$ & $\begin{array}{l}26.3(2.9) \\
16-30\end{array}$ \\
\hline Composite cognitive z-score & $\begin{array}{l}1.5(5.4) \\
-11.2 \text { to } 15.8\end{array}$ & $\begin{array}{l}1.7+(4.8) \\
19.2-11.3\end{array}$ \\
\hline
\end{tabular}

ISCED, The International Standard Classification of Education; CAG, cytosine-adenine-guanine; MMSE, Mini-Mental State Examination.

*Indicates a significant difference $(p<0.005)$ when compared with the control non-antidopaminergic medication group.

tIndicates a significant difference $(p<0.001)$ when compared with the control non-antidopaminergic medication group.

DBS, disease burden score; PBA, problems behavioural assessment; TFC, total functional capacity; UHDRS, Unified Huntington Disease Rating Scale.

changes in motor, cognitive or psychiatric decline. While this group also had a matched control group, the controls again had significantly less motor, psychiatric and cognitive impairment (see demographics table 3 and online supplementary table S5). Therefore, while the control group can provide an indication of the expected change in score over the 4-year time period in manifest HD patients, it comprises a somewhat clinically different group to those who start the medication.

\section{Group 1 HD antidopaminergic takers $(n=466)$ and HD controls (non-antidopaminergic takers) $(n=466)$}

There was no difference in the annual change in UHDRS motor score between groups $(\mathrm{F}(1,890)=8.359, \mathrm{p}=0.215)$, with antidopaminergic medication takers showing an average increase of $4.1 \pm 6.8$ points per year and controls showing an average increase of $3.5 \pm 7$ points (see table 4 and figure $1 \mathrm{~A}$ ). When each of the individual measures of the UHDRS motor score were considered, the antidopaminergic medication group exhibited a greater annual increase in their Luria tristep score $(p=0.002)$ and dysarthria $(\mathrm{p}=0.020)$ (data not shown), but a significantly 
Table 4 Group 1. average annual mean change in score for motor, psychiatric and cognitive measures per group (SD in brackets)

\begin{tabular}{|c|c|c|c|c|}
\hline & $\begin{array}{l}\text { Non-antidopaminergic } \\
\text { medication } \\
\text { takers } \\
(\mathrm{n}=466)\end{array}$ & $\begin{array}{l}\text { Antidopaminergic } \\
\text { medication } \\
\text { takers } \\
(\mathrm{n}=466)\end{array}$ & $P$ value & Cohen's d \\
\hline UHDRS total motor score & $\begin{array}{l}3.5 \\
(6.8)\end{array}$ & $\begin{array}{l}4.1 \\
(7)\end{array}$ & 0.215 & 0.09 \\
\hline UHDRS total chorea score & $\begin{array}{l}0.4 \\
(2.7)\end{array}$ & $\begin{array}{l}-0.1^{*} \\
(2.8)\end{array}$ & 0.004 & 0.18 \\
\hline $\begin{array}{l}\text { Irritability } \\
\text { (PBA) }\end{array}$ & $\begin{array}{l}0.3 \\
(3.6)\end{array}$ & $\begin{array}{l}-0.4^{*} \\
(3.1)\end{array}$ & 0.003 & 0.21 \\
\hline $\begin{array}{l}\text { Depression } \\
\text { (PBA) }\end{array}$ & $\begin{array}{l}-0.2 \\
(4.1)\end{array}$ & $\begin{array}{l}-0.3 \\
(5)\end{array}$ & 0.674 & 0.02 \\
\hline $\begin{array}{l}\text { Apathy } \\
\text { (PBA) }\end{array}$ & $\begin{array}{l}0.3 \\
(2.7)\end{array}$ & $\begin{array}{l}0.5 \\
(3.4)\end{array}$ & 0.391 & 0.07 \\
\hline Composite cognitive z-score & $\begin{array}{l}0.8 \\
(3.5)\end{array}$ & $\begin{array}{l}-0.8 \dagger \\
(4.8)\end{array}$ & $<0.001$ & 0.4 \\
\hline TFC score & $\begin{array}{l}-0.5 \\
(1.4)\end{array}$ & $\begin{array}{l}-1^{*} \\
(1.4)\end{array}$ & $<0.001$ & 0.35 \\
\hline UHDRS independence scale & $\begin{array}{l}-2.5 \\
(6)\end{array}$ & $\begin{array}{l}-3.8^{*} \\
(6.8)\end{array}$ & 0.004 & 0.2 \\
\hline
\end{tabular}

$P$ values are from a univariate analysis of variance (ANOVA) with age and CAG as covariates.

*Indicates a significant difference $(p<0.005)$ when compared with the control non-antidopaminergic medication group.

tIndicates a significant difference $(p<0.001)$ when compared with the control non-antidopaminergic medication group.

PBA, problems behavioural assessment; TFC, total functional capacity; UHDRS, Unified Huntington Disease Rating Scale.

smaller annual increase in chorea score when compared with those not on the treatment $(0.4 \pm 2.8$ vs $-0.1 \pm 2.7$ points, $F(1$, $895)=8.674, p=000$, table 4 and figure $1 B$ ).

Similarly, the antidopaminergic medication group displayed a significantly lower annual increase in the irritability score compared with non-takers $(-0.4 \pm 3.6$ points vs $0.3 \pm 3.1$ points, $\mathrm{F}(1,895)=8.674, \mathrm{p}=0.003$ ) (see table 4 and figure 1C). In contrast, there were no differences between groups for depression $(\mathrm{F}(1,905)=0.178, \mathrm{p}=0.674)$ or apathy $(\mathrm{F}(1,912)=1.711$, $\mathrm{p}=0.391$ ) (see table 4). As this analysis included participants who scored zero for these measures, we repeated the analysis including only those prescribed the medication specifically for depression or apathy. There were still no differences in the rate of change between groups for either problem (data not shown).

We next assessed the effect of antidopaminergic medication on cognitive performance (see table 4 for the composite cognitive $\mathrm{z}$-score and online supplementary table S6 for the results of each individual cognitive task). HD patients taking antidopaminergic medication had a significantly lower $\mathrm{z}$-score than nontakers $(-0.8 \pm 4.8$ vs $0.8 \pm 3.5, \mathrm{~F}(1,902)=29.161, \mathrm{p}<0.001)$ indicative of greater impairment (see figure 1D). In terms of the individual cognitive tasks, the antidopaminergic group exhibited a greater decline in all tasks $(p<0.001)$, except Trail making A score $(p=0.325)$. A multiple linear regression showed the degree of decline in composite cognitive $\mathrm{z}$-score was significantly predicted by group (antidopaminergic takers vs nontakers), but not by gender, age, CAG repeat length, DBS, TFC, time since diagnosis, ISCED or by motor or psychiatric scores ( $F$ $\left.(12,878)=3.439, \mathrm{p}<0.001, \mathrm{R}^{2}=0.045\right)$ (see table 5).

Finally, the antidopaminergic medication group had significantly greater decreases in UHDRS TFC score (F (1, $896)=32.993, \mathrm{p}<0.001)$ and UHDRS independence score $(\mathrm{F}$ $(1,895)=8.482, p=0.004$, see table 4$)$, indicative of a greater annual loss in function and independence.

The earlier pattern of results was also found when propensity matching was not performed and the two groups were compared using a multivariate ANOVA with age, gender, CAG repeat length, DBS, TFC and time since diagnosis as the variables (see online supplementary table S2).

Group 2 Pre-HD and post-HD antidopaminergic takers $(\mathrm{n}=90)$ and matched HD controls (non-antidopaminergic takers) $(n=108)$

Next, we selected a separate group of antidopaminergic medication takers with at least two assessments prior to starting the medication and two assessments after starting the medication (see table 6 and figure 2A-D). Onset of the medication led to a reduction in the average annual increase in UHDRS motor score (from $5.7 \pm 11.2$ points to $2.9 \pm 9.2$ points), which did not reach significance $(\mathrm{t}(74)=1.178, \mathrm{p}=0.079)$. This was because of a significantly reduced annual increase in UHDRS chorea score post-medication $(1.1 \pm 4.7$ points vs $-0.5 \pm 5.5$ points, $t$ $(89)=2.122, p=0.037$ ), (see table 6 and figure $2 \mathrm{~B}$ as well as a significant decrease in saccade initiation) (from a $0.6 \pm 1.5$-point increase to a $0.03 \pm 1.7$-point increase $\mathrm{p}=0.020)$. In contrast, all other measures of UHDRS motor score remained stable premedication and post-medication (data not shown).

By comparison, the matched control group displayed no significant changes in motor $(\mathrm{t}(101)=0.239, \mathrm{p}=0.265)$ or chorea scores $(\mathrm{t}(98)=0.951, \mathrm{p}=0.344)$. Thus, while the antidopaminergic group showed significantly greater increases in motor score than the control group pre-medication $(\mathrm{F}(1,171)=4.392$, $\mathrm{p}=0.038)$, they showed an equivalent rate of increase to controls post-medication $(F(1,169)=0.012, p=0.914)$, together with a significantly lower increase in chorea score $(F(1,183)=4.867$, $\mathrm{p}=0.029$ ).

There were, though, no differences found before or after onset of antidopaminergic medication in terms of depression $(\mathrm{t}$ $(76)=0.665, \mathrm{p}=0.508)$ or apathy $(\mathrm{t}(78)=0.853, \mathrm{p}=0.00 .396)$ (see table 6). Similarly, the matched control group showed no significant change in these measures across the same time intervals. However, for irritability, while both groups had similar rates of decline during time interval 1 , the group starting antidopaminergic medication displayed a strong trend for a reduced rate of increase in post-medication $(\mathrm{t}(78)=1.872, \mathrm{p}=0.065)$, 


\section{Group 1}

A

Total Motor score (UHDRS)

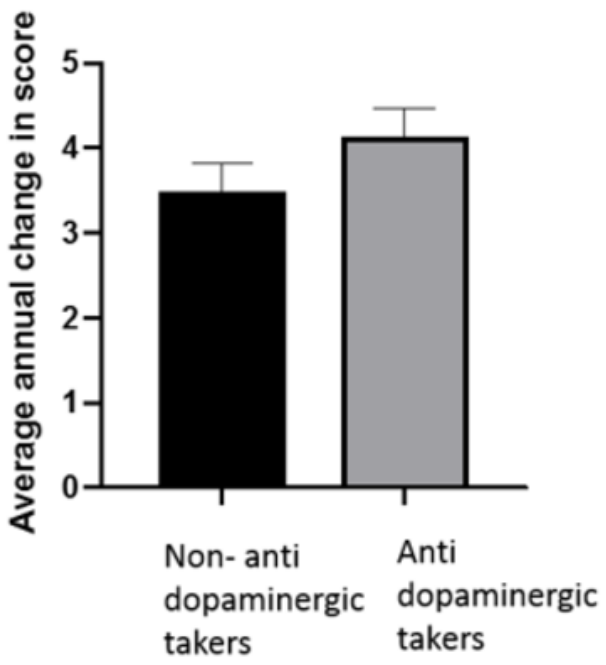

C
B

Total Chorea score (UHDRS)

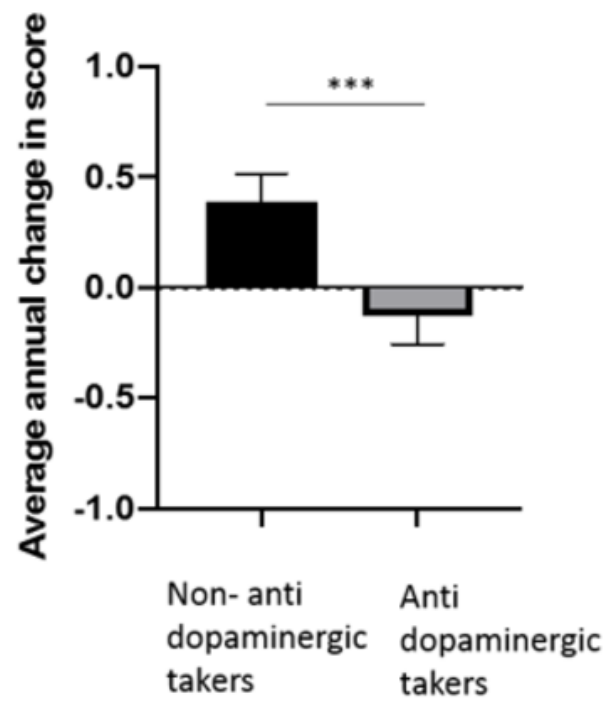

D
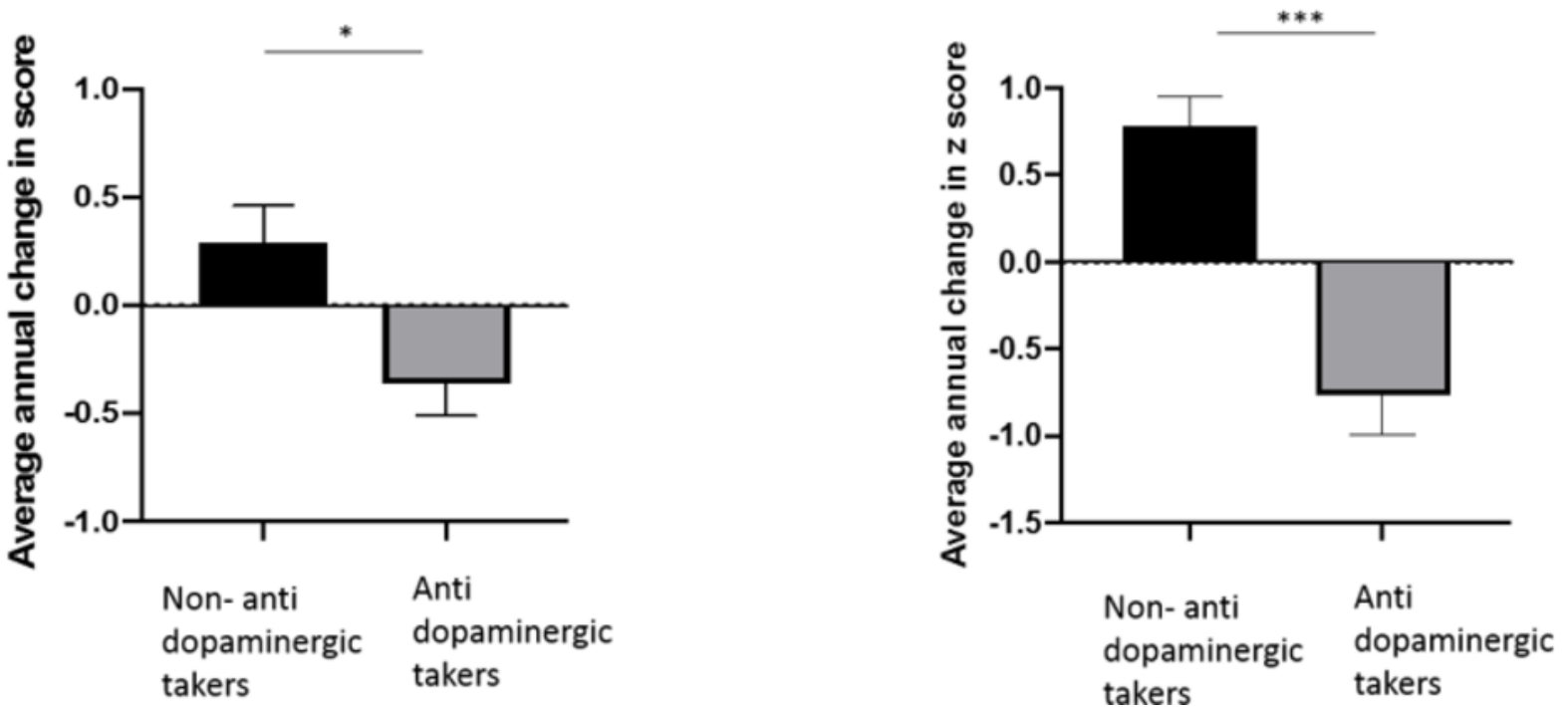

Figure 1 Graphs showing average annual change in UHDRS total motor score, PBA irritability and composite cognitive score per group. Group 1. (A) There is no difference in the annual increase in UHDRS total motor score between HD antidopaminergic medication takers and HD non-antidopaminergic medication takers. (B) HD patients taking antidopaminergic medication had a significantly reduced increase in chorea score compared with HD controls not taking antidopaminergic medication. (C) Antidopaminergic medication takers had a significantly smaller increase in reported irritability on the PBA compared with patients not on DA altering medications.(D) HD antidopaminergic medication takers had a statistically faster rate of cognitive decline than HD patients not taking these drugs. Groups were compared using univariate analysis with age, CAG and gender as covariates. Mean and SE of the mean are shown. ${ }^{* * *} p<0.001 . n=466$ per group. DA, dopamine; HD, Huntington's disease; PBA, problems behavioural assessment; UHDRS, Unified Huntington Disease Rating Scale. 
Table 5 Group 1. Multivariate regression analysis showing factors associated with change in composite cognitive score

\begin{tabular}{llc}
\hline & \multicolumn{2}{l}{ Change in total cognitive z-score } \\
\cline { 2 - 3 } Predictor variable & B coefficient & P value \\
\hline Constant & -1.689 & 0.781 \\
Group (antidopaminergic takers vs non- & -1.244 & $<0.001$ \\
antidopaminergic takers) & & \\
Age & 0.046 & 0.071 \\
Gender & 0.083 & 0.493 \\
CAG repeat length & 0.094 & 0.430 \\
DBS & -0.008 & 0.008 \\
TFC & -0.039 & 0.586 \\
Time since diagnosis & 0.020 & 0.619 \\
UHDRS total motor score & -0.003 & 0.813 \\
Depression (PBA) & -0.012 & 0.659 \\
Irritability (PBA) & -0.059 & 0.087 \\
Apathy (PBA) & 0.030 & 0.445 \\
ISCED & -0.155 & 0.183 \\
\hline ISCED, The International Standard Classification of Education; CAG, cytosine- \\
adenine-guanine. \\
DBS, disease burden score; PBS, problems behavioural assessment; TFC, total \\
functional capacity; UHDRS, Unified Huntington Disease Rating Scale.
\end{tabular}

which meant that they had a significantly lower average increase than the matched control group during time interval 2 (F (1, $175)=10.061, p=0.002$ ) (see figure $2 \mathrm{C}$ ).

Those prescribed antidopaminergic medication also showed a significant decrease in cognitive z-score post-medication, with a z-score of $0.8 \pm 3.4$ before medication and $-0.7 \pm 3.4$, postmedication $(\mathrm{t}(76)=3.332, \mathrm{p}=0.001)$ (see table 6 and figure $2 \mathrm{D}$ ). This was driven by a greater decline in the verbal fluency, Stroop word and interference and the Trail making B tasks $(p<0.05$, see online supplementary table S7), whereas there were no significant differences for SDMT, Stroop naming or Trail making A pre-medication and post-medication $(\mathrm{p}>0.05)$. In comparison, the matched controls displayed no change in z-score or in any individual cognitive task over the time intervals $(t)(92)=1.293$, $\mathrm{p}=0.199$ ).

Finally, for the antidopaminergic medication group, there were no differences in annual change in score pre-medication or post-medication for TFC $(t(80)=0.435, p=0.664)$ or independence scales $(\mathrm{t}(80)=1.342, \mathrm{p}=0.184$, table 6 ), suggesting that the medication did not directly impact on how the disease affects functional capacity. Similarly, the matched control group didn't show any significant changes in annual progression of these measures at different time points (see table 6).

\section{DISCUSSION}

This study interrogated the Enroll-HD database to investigate effects of antidopaminergic treatments on motor, cognitive and psychiatric function over a 3-year period.

\section{Effect of antidopaminergic medication on function and independence}

Those on antidopaminergic medication showed a greater annual decline in TFC and independence scores than those who were not. However, seeing as there were no differences in the rate of change in these measures following the onset of the antidopaminergic medication, this is unlikely to be a result of the dopaminergic medication itself, and may instead reflect the fact that this group had a more severe disease profile at baseline.

\section{Effect of antidopaminergic medication on motor features}

The annual increase in UHDRS chorea score over a 3-year period was, not surprisingly, significantly lower in HD patients taking

Table 6 Group 2. Average annual mean change in score for pre-antidopaminergic and post-antidopaminergic takers and matched controls (SD in brackets)

\begin{tabular}{|c|c|c|c|c|c|c|c|c|}
\hline & $\begin{array}{l}\text { Control group } \\
\text { (time 1) } \\
(n=103)\end{array}$ & $\begin{array}{l}\text { Control group } \\
\text { (time 2) } \\
(n=103)\end{array}$ & $P$ value & Cohen's d & $\begin{array}{l}\text { Pre-antidopaminergic } \\
\text { medication } \\
(\text { time 1) } \\
(n=90)\end{array}$ & $\begin{array}{l}\text { Post- } \\
\text { antidopaminergic } \\
\text { Medication } \\
\text { (time 2) } \\
(\mathrm{n}=90)\end{array}$ & $P$ value & Cohen's d \\
\hline UHDRS total motor score & $\begin{array}{l}2.4 \\
(7.9)\end{array}$ & $\begin{array}{l}2.7 \\
(7.6)\end{array}$ & 0.819 & 0.04 & $\begin{array}{l}5.7 \\
(11.2)\end{array}$ & $\begin{array}{l}2.9 \\
(9.2)\end{array}$ & 0.079 & 0.27 \\
\hline UHDRS total chorea score & $\begin{array}{l}0.4 \\
(4.5)\end{array}$ & $\begin{array}{l}1 \\
(4.2)\end{array}$ & 0.344 & 0.14 & $\begin{array}{l}1.1 \\
(4.7)\end{array}$ & $\begin{array}{l}-0.5^{*} \\
(5.5)\end{array}$ & 0.036 & 0.31 \\
\hline UHDRS saccade initiation & $\begin{array}{l}0.4 \\
(1.4)\end{array}$ & $\begin{array}{l}0.1 \\
(1.4)\end{array}$ & 0.100 & 0.21 & $\begin{array}{l}0.6 \\
(1.5)\end{array}$ & $\begin{array}{l}0.03^{*} \\
(1.7)\end{array}$ & 0.020 & 0.35 \\
\hline $\begin{array}{l}\text { Irritability } \\
\text { (PBA) }\end{array}$ & $\begin{array}{l}0.4 \\
(4)\end{array}$ & $\begin{array}{l}0.6 \\
(3.4)\end{array}$ & 0.745 & 0.05 & $\begin{array}{l}0.1 \\
(6.2)\end{array}$ & $\begin{array}{l}-1.8 \\
(6.2)\end{array}$ & 0.065 & 0.31 \\
\hline $\begin{array}{l}\text { Depression } \\
\text { (PBA) }\end{array}$ & $\begin{array}{l}-0.1 \\
(4.1)\end{array}$ & $\begin{array}{l}-0.1 \\
(4.5)\end{array}$ & 0.962 & 0 & $\begin{array}{l}0.8 \\
(6.2)\end{array}$ & $\begin{array}{l}-0.2 \\
(6.7)\end{array}$ & 0.508 & 0.2 \\
\hline $\begin{array}{l}\text { Apathy } \\
\text { (PBA) }\end{array}$ & $\begin{array}{l}0.02 \\
(2.9)\end{array}$ & $\begin{array}{l}0.3 \\
(3.3)\end{array}$ & 0.474 & 0.09 & $\begin{array}{l}0.3 \\
(4)\end{array}$ & $\begin{array}{l}0.9 \\
(4.9)\end{array}$ & 0.396 & 0.13 \\
\hline $\begin{array}{l}\text { Total composite cognitive z- } \\
\text { score }\end{array}$ & $\begin{array}{l}0.4 \\
(3.9)\end{array}$ & $\begin{array}{l}-0.3 \\
(4)\end{array}$ & 0.199 & 0.18 & $\begin{array}{l}0.8 \\
(3.4)\end{array}$ & $\begin{array}{l}-0.7^{* * *} \\
(3.4)\end{array}$ & 0.001 & 0.44 \\
\hline TFC score & $\begin{array}{l}-0.6 \\
(1.3)\end{array}$ & $\begin{array}{l}-0.4 \\
(1.6)\end{array}$ & 0.483 & 0.13 & $\begin{array}{l}-0.9 \\
(1.8)\end{array}$ & $\begin{array}{l}-1 \\
(1.6)\end{array}$ & 0.664 & 0.05 \\
\hline UHDRS independence scale & $\begin{array}{l}-3.1 \\
(7.6)\end{array}$ & $\begin{array}{l}-1.8 \\
(9.5)\end{array}$ & 0.3 & 0.15 & $\begin{array}{l}-5.2 \\
(9.5)\end{array}$ & $\begin{array}{l}-3.6 \\
(7.3)\end{array}$ & 0.183 & 0.18 \\
\hline
\end{tabular}

$P$ values are from paired t-tests.

*Indicates a significant difference $(p<0.005)$ when compared with the control non-antidopaminergic medication group. tIndicates a significant difference $(\mathrm{p}<0.001)$ when compared with the control non-antidopaminergic medication group. PBA, problems behavioural assessment; TFC, total functional capacity; UHDRS, Unified Huntington Disease Rating Scale. 


\section{Group 2}

A

Total Motor score (UHDRS)

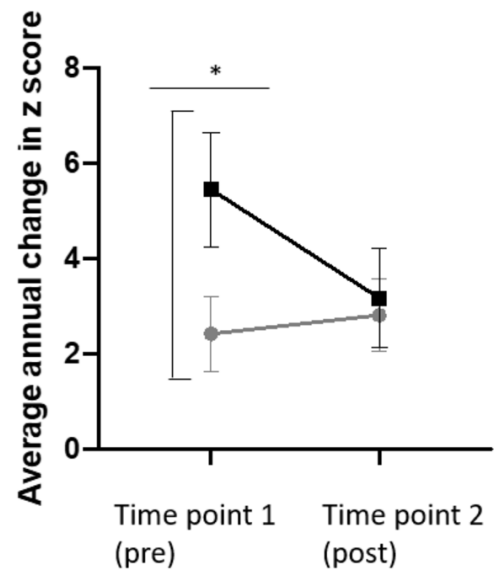

C Irritability (PBA)

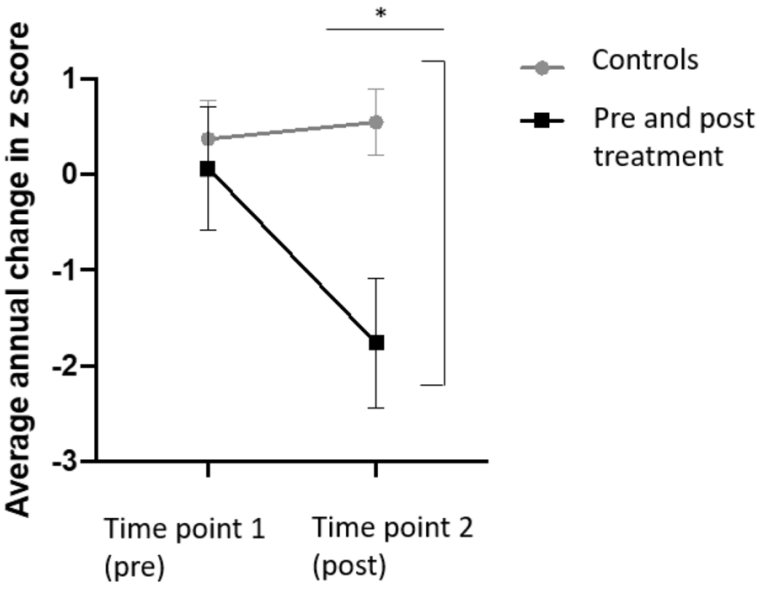

treatment

B

Total Chorea score (UHDRS)

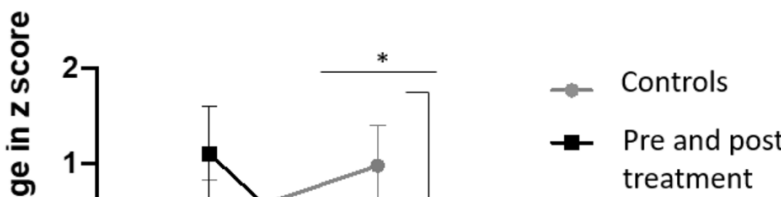

D

Composite cognitive z score

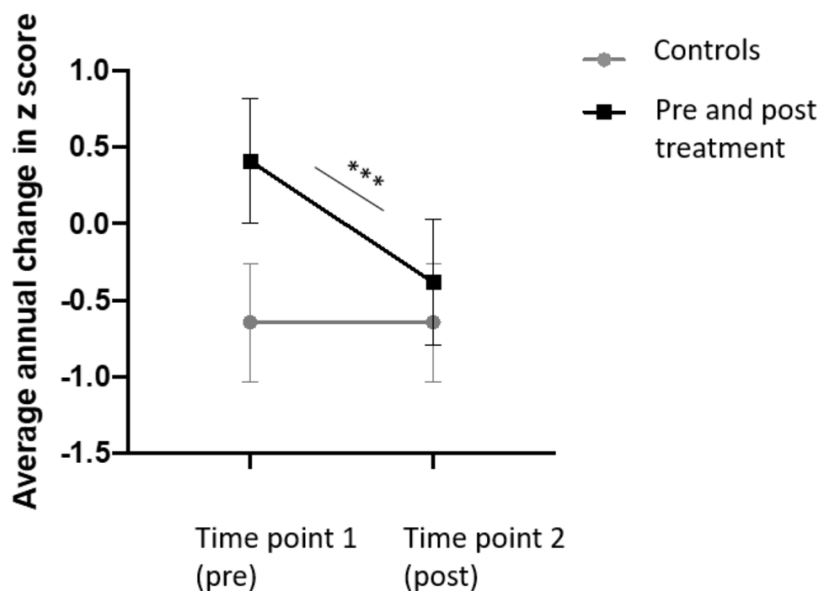

Figure 2 Graphs showing average annual change in UHDRS total motor score, PBA irritability and composite cognitive score per group. Group 2. (A) HD patients who had a period of assessment before being prescribed antidopaminergic medications did not show a significant difference in annual change in motor score pre-antidopaminergic and post-antidopaminergic medication introduction. Matched controls also did not show a significant difference across the two time intervals. (B) HD patients showed a diminished increase in chorea score in the period after they were prescribed the antidopaminergic medication. In contrast, matched controls did not show significant changes in chorea score between the two time intervals. (C) The onset of antidopaminergic medication did not have a significant effect on PBA irritability scores. Matched controls also did not display significant changes in irritability score. (D) HD patients who began antidopaminergic medication showed a significantly faster rate of cognitive decline in the period after medication introduction. In contrast, matched controls did not show any change in cognitive score. A paired t-test compared scores of time interval 1 (preantidopaminergic medication) with time interval 2 (post-antidopaminergic medication). A univariate ANOVA compared scores of each group during each time interval with age, CAG and gender as covariates. $p<0.05 . n=81$ pairs. HD, Huntington's disease; PBA, problems behavioural assessment; UHDRS, Unified Huntington Disease Rating Scale.

antidopaminergic medication compared with HD patients who were not. Furthermore, HD patients beginning antidopaminergic medication part way through the study showed a significant 1.6-point reduction in chorea score on the UHDRS after starting the medication. This result is to be anticipated especially given the results of two clinical trials assessing tetrabenazine (TETRA-HD, 
Huntington Study Group ${ }^{22}$ ) and its modified form, deutetrabenazine (FIRST-HD, Frank et $a l^{23}$ ), which, respectively, showed a 3.5 -point and 2.5-point reduction in UHDRS chorea score, after 12 weeks of treatment. The smaller reduction obtained in this study may be explained by differences between the studies, eg differences in duration of treatment, sample population and most importantly our study looked at a number of different antidopaminergic medications (see table 1 ).

In regard to the DA antagonists which are commonly prescribed off-label in HD, there have been a few small openlabel studies which showed significant improvements in psychiatric measures but inconsistent motor effects, with some studies showing improvement, ${ }^{24}$ some stabilisation ${ }^{26}$ and some no change. $^{27}$ One open label study with olanzapine showed a 1.6point reduction in UHDRS chorea score in 11 HD patients after 6 months ${ }^{28}$ which is in line with our results. Our analysis is the first to assess the longitudinal effects of DA antagonists in a large sample of participants and provides evidence in support of their beneficial effect for the treatment of chorea in HD.

Interestingly, we also found that antidopaminergic medication was associated with an improvement in saccade initiation deficits. It is well established that the basal ganglia controls the initiation of eye movements via inhibition of the superior colliculus. ${ }^{29}$ However, evidence for a role of DA in this process in humans is lacking, although a correlation between the degree of striatal DA transporter binding and the severity saccadic errors has been reported in patients with Parkinson's disease. ${ }^{30}$ Importantly, this study suggests that the onset of antidopaminergic medication may improve saccade initiation in HD, but further work is needed to explore this.

A recent retrospective analysis of the EHDN (European Huntington's Disease Network) REGISTRY study showed that in contrast to our results, antidopaminergic medication takers had a greater annual increase in UHDRS total motor score (including oculomotor dysfunction), compared with a control group. ${ }^{31}$ The authors also showed that the annualised progression of chorea and dystonia did not differ between the groups. Crucially, the two groups weren't matched on demographic or clinical variables, meaning that the antidopaminergic group were older, had a longer disease duration and also a higher disease burden score, and therefore a faster disease progression may have been expected. The fact that chorea and dystonia did not differ between the two groups, even in these circumstances, suggests that the antidopaminergic medication may have been of some benefit to these features of the disease. Our study suggests that if the groups were better matched, improvements in chorea and saccade initiation may have become apparent.

Effect of antidopaminergic medication on psychiatric features HD patients on antidopaminergic medication showed a reduced annual increase in irritability scores compared with HD patients who were not, suggesting this medication may be beneficial in treating irritability in HD. These results support case studies highlighting the efficiency of olanzapine, ${ }^{28} 3233$ risperidone ${ }^{25}$ and quetiapine $^{26}$ in treating this aspect of HD. However, we found that these drugs did not appear to impact on annual changes in apathy or depression scores, suggesting that while the medication is not improving apathy it is also not making it worse. Theoretically, reducing levels of DA could lead patients to experience a reduction in their motivation and given that apathy is a prominent feature of $\mathrm{HD}$, these drugs might have been predicted to make this aspect of their symptomatology worse. This was not seen and is in line with a recent trial showing that bupropion was ineffective for treating this symptom. ${ }^{34}$ However, randomised controlled trials, which include detailed scales to assess these conditions, are needed to more thoroughly explore the role of DA in depression and apathy in HD.

Effect of antidopaminergic medication on cognitive features Assessment of the effects of antidopaminergic medication on the cognitive tasks performed in Enroll-HD is of particular importance given the impact these problems have on quality of life. We found that HD patients on antidopaminergic medication had a more rapid annual cognitive decline than HD patients who were not. Studies of cognition in healthy individuals have also shown that DA antagonists can be detrimental to cognition. ${ }^{35-37}$ Exactly why this should be the case is unclear, but it is known that DA modulates cognition in an inverted $U$ function whereby both excessive and insufficient DA is detrimental to certain cognitive processes in healthy individuals ${ }^{16}$ and thus it may be that these drugs in HD move patients away from their optimal DA level.

Importantly, as this is an observational study, causality cannot be established, and it is possible that the differences viewed between the groups were driven by other unknown factors unrelated to DA or the other variables we controlled for. Furthermore, there was innate bias in the data set as those taking antidopaminergic had a more severe disease phenotype and therefore may represent a subgroup of HD with faster HD-related cognitive deterioration, irrespective of medication, as we have reported previously. $^{38} 39$

We sought to try and investigate this by looking at the speed of cognitive decline before and after antidopaminergic drugs were started. We found again that cognition worsened significantly in HD patients in the period subsequent to taking antidopaminergic medication for four of the seven cognitive tasks and this was not observed in the control group. Interestingly, two of these tasks (Trail making B and Stroop interference), require flexibility and set-shifting, processes known to be dependent on dopamine. However, while the tasks included in Enroll-HD are useful tools to obtain a basic indication of cognitive function, the battery was not designed specifically to be sensitive to DA-dependent cognitive processes. Future research should study the effects of DA antagonism on cognition in HD in a more controlled manner, using tasks specific to the function of DA.

This study has a number of other limitations outside of the bias in terms of patient selection to the database. For example, scores on a particular day could be affected by a number of factors, such as tiredness, mood or other medications. Furthermore, some of the DA antagonists included in the study do not selectively act on DA receptors but also block other receptors, eg serotonin receptors. Since manipulations of serotonin have been shown to induce changes in cognitive functioning, ${ }^{40}$ it cannot be ruled out that the results of this study were influenced by changes in levels of serotonin in addition to dopamine.

Despite these drawbacks, this is the first study to assess the longitudinal effects of antidopaminergic medication on each of the major clinical aspects of HD. The results suggest that the medication is beneficial in treating chorea and irritability but may not influence apathy and depression. Antidopaminergic medication also appears to be associated with worsening cognition, which has important clinical implications since patients often report cognitive impairments to be more disruptive to daily life than motor disturbances. However, more controlled prospective studies are needed to fully elucidate the causative role of DA in cognitive impairments in HD and/or whether there are subtypes of disease that should be treated differently. 
Acknowledgements The authors would like to thank the patients and their families who participate in this study. The Enroll-HD is a CHDI Foundation Project and therefore we would like to thank the CHDI Foundation for granting us access to the Enroll-HD database.

Contributors $\mathrm{KH}$ designed the experiments, conducted the data analysis and wrote the manuscript. W-LK advised on the statistical analysis and revised the manuscript. SLM conceived and designed the experiments, advised on statistical analysis and revised the manuscript. RAB designed the experiments and revised the manuscript.

Funding This research has been funded/supported by the National Institute for Health Research Rare Diseases Translational Research Collaboration (NIHR RD-TRC).

Disclaimer The views expressed are those of the author(s) and not necessarily those of the National Health Service, the National Institute for Health Research (NIHR) or the Department of Health. We would also like to thank the NIHR Cambridge Biomedical Research Centre, Dementia and Neurodegeneration Theme (146281). RAB is an NIHR Senior Investigator (NF-SI-0616-10011) and is supported by the WT/MRC Stem Cell Institute (203151/Z/16/Z).

Competing interests None declared.

Patient consent for publication Not required.

Provenance and peer review Not commissioned; externally peer reviewed.

Data availability statement Data are available upon reasonable request. Researchers can request access to the Enroll-HD data set at (https://www.enroll-hd. org)

Open access This is an open access article distributed in accordance with the Creative Commons Attribution Non Commercial (CC BY-NC 4.0) license, which permits others to distribute, remix, adapt, build upon this work non-commercially, and license their derivative works on different terms, provided the original work is properly cited, appropriate credit is given, any changes made indicated, and the use is non-commercial. See: http://creativecommons.org/licenses/by-nc/4.0/.

ORCID iD

Kate L Harris http://orcid.org/0000-0002-6683-4337

\section{REFERENCES}

1 Lawrence AD, Sahakian BJ, Hodges JR, et al. Executive and mnemonic functions in early Huntington's disease. Brain 1996;119:1633-45.

2 Migliore S, D'Aurizio G, Curcio G, et al. Task-switching abilities in pre-manifest Huntington's disease subjects. Parkinsonism Relat Disord 2019;60:111-7.

3 Mason SL, Zhang J, Begeti F, et al. The role of the amygdala during emotional processing in Huntington's disease: from pre-manifest to late stage disease. Neuropsychologia 2015;70:80-9.

4 Paulsen JS, Ready RE, Hamilton JM, et al. Neuropsychiatric aspects of Huntington's disease. J Neurol Neurosurg Psychiatry 2001;71:310-4.

5 Craufurd D, Thompson JC, Snowden JS. Behavioral changes in Huntington disease. Neuropsychiatry Neuropsychol Behav Neurol 2001;14:219-26.

6 Bachoud-Lévi A-C, Ferreira J, Massart R, et al. International guidelines for the treatment of Huntington's disease. Front Neurol 2019;10:710.

7 Martinez-Horta S, Perez-Perez J, van Duijn E, et al. Neuropsychiatric symptoms are very common in premanifest and early stage Huntington's disease. Parkinsonism Relat Disord 2016;25:58-64.

8 Julien CL, Thompson JC, Wild S, et al. Psychiatric disorders in preclinical Huntington's disease. J Neurol Neurosurg Psychiatry 2007;78:939-43.

9 Reading SAJ, Dziorny AC, Peroutka LA, et al. Functional brain changes in presymptomatic Huntington's disease. Ann Neurol 2004;55:879-83.

10 Vonsattel JP, Difiglia M. Huntington disease. J Neuropathol Exp Neurol 1998:57:369-84.

11 Mink JW, Thach WT. Basal ganglia intrinsic circuits and their role in behavior. Curr Opin Neurobiol 1993;3:950-7.

12 Paleacu D. Tetrabenazine in the treatment of Huntington's disease. Neuropsychiatr Dis Treat 2007;3:545.
13 Nieoullon A. Dopamine and the regulation of cognition and attention. Prog Neurobiol 2002:67:53-83

14 Adam R, Leff A, Sinha N, et al. Dopamine reverses reward insensitivity in apathy following globus pallidus lesions. Cortex 2013:49:1292-303.

15 Belujon P, Grace AA. Dopamine system dysregulation in major depressive disorders. Int I Neuropsychopharmacol 2017;20:1036-46.

16 Cools R, D'Esposito M. Inverted-U-shaped dopamine actions on human working memory and cognitive control. Biol Psychiatry 2011;69:e113-25.

17 Bäckman L, Robins-Wahlin TB, Lundin A, et al. Cognitive deficits in Huntington's disease are predicted by dopaminergic PET markers and brain volumes. Brain 1997;120:2207-17.

18 Landwehrmeyer GB, Fitzer-Attas CJ, Giuliano JD, et al. Data analytics from Enroll-HD, a global clinical research platform for Huntington's disease. Mov Disord Clin Pract 2017:4:212-24.

19 Montoya-Murillo G, Ibarretxe-Bilbao N, Peña J, et al. The impact of apathy on cognitive performance in the elderly. Int I Geriatr Psychiatry 2019;34:657-65.

20 Elze MC, Gregson J, Baber U, et al. Comparison of propensity score methods and covariate adjustment: evaluation in 4 cardiovascular studies. J Am Coll Cardiol 2017;69:345-57.

21 Penney JB, Vonsattel JP, MacDonald ME, et al. Cag repeat number governs the development rate of pathology in Huntington's disease. Ann Neurol 1997:41:689-92.

22 Huntington Study Group. Tetrabenazine as antichorea therapy in Huntington disease: a randomized controlled trial. Neurology 2006;66:366-72.

23 Huntington Study Group, Frank S, Testa CM, et al. Effect of deutetrabenazine on chorea among patients with Huntington disease: a randomized clinical trial. JAMA 2016:316:40-50.

24 Quinn N, Marsden CD. A double blind trial of sulpiride in Huntington's disease and tardive dyskinesia. J Neurol Neurosurg Psychiatry 1984;47:844-7.

25 Koller WC, Trimble J. The gait abnormality of Huntington's disease. Neurology 1985:35:1450

26 Duff K, Beglinger LJ, O'Rourke ME, et al. Risperidone and the treatment of psychiatric, motor, and cognitive symptoms in Huntington's disease. Ann Clin Psychiatry 2008:20:1-3.

27 Alpay M, Koroshetz WJ. Quetiapine in the treatment of behavioral disturbances in patients with Huntington's disease. Psychosomatics 2006:47:70-2.

28 Squitieri F, Cannella M, Porcellini A, et al. Short-Term effects of olanzapine in Huntington disease. Neuropsychiatry Neuropsychol Behav Neurol 2001;14:69-72.

29 Hikosaka O, Sakamoto M, Usui S. Functional properties of monkey caudate neurons. II. visual and auditory responses. J Neurophysiol 1989;61:799-813.

30 Railo H, Olkoniemi H, Eeronheimo E, et al. Dopamine and eye movement control in Parkinson's disease: deficits in corollary discharge signals? PeerJ 2018;6:e6038.

31 Tedroff J, Waters S, Barker RA, et al. Antidopaminergic medication is associated with more rapidly progressive Huntington's disease. J Huntingtons Dis 2015;4:131-40.

32 Bogelman G, Hirschmann S, Modai I. Olanzapine and Huntington's disease. J Clin Psychopharmacol 2001;21:245-6.

33 Grove VE, Quintanilla J, DeVaney GT. Improvement of Huntington's disease with olanzapine and valproate. N Engl J Med 2000;343:973-4.

34 Gelderblom H, Wüstenberg T, McLean T, et al. Bupropion for the treatment of apathy in Huntington's disease: a multicenter, randomised, double-blind, placebo-controlled, prospective crossover trial. PLoS One 2017:12:e0173872.

35 Ramaekers JG, Louwerens JW, Muntjewerff ND, et al. Psychomotor, cognitive, extrapyramidal, and affective functions of healthy volunteers during treatment with an atypical (amisulpride) and a classic (haloperidol) antipsychotic. J Clin Psychopharmacol 1999;19:209-21.

36 Saeedi H, Remington G, Christensen BK. Impact of haloperidol, a dopamine D2 antagonist, on cognition and mood. Schizophr Res 2006;85:222-31.

37 Vernaleken I, Kumakura Y, Cumming P, et al. Modulation of [18F]fluorodopa (FDOPA) kinetics in the brain of healthy volunteers after acute haloperidol challenge. Neuroimage 2006:30:1332-9.

38 Vuono R, Winder-Rhodes S, de Silva R, et al. The role of tau in the pathological process and clinical expression of Huntington's disease. Brain 2015;138:1907-18.

39 Kuan WL, Kasis A, Yuan Y, et al. Modelling the natural history of Huntington's disease progression. J Neurol Neurosurg Psychiatry 2015;86:1143-9.

40 Schmitt JAJ, Wingen M, Ramaekers JG, et al. Serotonin and human cognitive performance. Curr Pharm Des 2006;12:2473-86. 